\section{Concentration of Wear Products in Hair, Blood, and Urine after Total Hip Replacement}

\author{
R. F. COLEMAN, J. HERRINGTON, \\ JOHN T. SCALES
}

British Medical fournal, 1973, 1, 527-529

\begin{abstract}
Summary
Raised levels of cobalt and chromium are found in the blood and urine of patients with metallic total hip replacements. When one of the hip components is made of polyethylene much less metal seems to be released from the joint. The long-term effects of the accumulation of chromium in the body need to be studied further.
\end{abstract}

\section{Introduction}

Cast cobalt chromium molybdenum alloy (C cast alloy) has been used for implants since 1939. Generally this alloy is well tolerated by the tissues although there have been a few cases of apparent sensitivity to its constituents. McKenzie et al. (1967), reported a case of pruritus and generalized urticaria which persisted for 10 months after the insertion of a Smith Peterson C cast alloy nail. During that time the patient suffered attacks of anginal congestive heart failure and three episodes of cerebral thrombosis. Patch testing showed a response to a solution of $2 \%$ nickel sulphate at 48 hours. A similar response was illustrated when a $C$ cast alloy nail was strapped to the thigh for $\mathbf{4 8}$ hours. Twenty-four hours after removal of the original implant the urticaria resolved. One of us (J.T.S.) has been concerned with four other cases of apparent sensitivity to the alloy. In three of these cases the patient was sensitive to nickel. In these cases the $C$ cast alloy implants were replaced by titanium-318 implants. In the other patient the implants were removed.

Since 1962 increasing use has been made of the $C$ cast alloy specified in B.S. 3531 : 1962 and 1968 for all metal total hip replacements (T.H.R.s) where the liberation of metallic ions and wear debris has been on a greater scale than hitherto.

The tissues around $C$ cast alloy T.H.R.s and major bone replacements often have a black appearance. However, histological and electron probe analysis studies have shown surprisingly small amounts of metallic wear products. Perivascular cuffing with macrophages containing black particles is frequently seen, and sometimes local lymphocytic infiltration and giant cell formation with areas of local necrosis are found. The perivascular cuffing suggests that the debris is being transported to some other part of the body. Cultures of tissues

Atomic Weapons Research Establishment, Aldermaston, Berks R. F. COLEMAN, B.SC., Principal Scientific Officer, Chemistry Division J. HERRINGTON, B.SC., A.R.I.C., Higher Scientific Officer, Chemistry
Division

Department of Biomedical Engineering, Institute of Orthopaedics (University of London), Stanmore, Middlesex, HA7 4LP

JOHN T. SCALES, P.R.C.S., C.I.MECH.E., Reader in Biomedical Engineering showing these histological changes have in most cases been sterile. In patients from whom organisms have been recovered there was a history of clinical infection.

Since the alloy contains known tanning agents the wear products may be chelated with albumin or globulin present in the synovial-like fluid found in the capsule around the implant. There is also the possibility that soluble products of the heavy metals in C cast alloy T.H.R.s may form metallic salts.

Neurological, renal, and cardiovascular changes occurring after the administration of cobalt and certain of its salts to man and animals have been reported (Weissbecker, 1950; Gardner, 1953; Holly, 1955; Kriss, et al., 1955; De Moraes and Mariano, 1967; Schirrmacher, 1967; Hall and Smith, 1968; Schroeder and Nason, 1969). Because of the histological findings and clinical reports it was thought that a long-term study of the distribution and route of excretion of the wear products in patients with T.H.R.s was required.

\section{Present Study}

At the request of J.T.S. the Department of Health and Social Security asked the Atomic Weapons Research Establishment to investigate the concentration of cobalt and chromium in the hair, blood, and urine resulting from the use of these implants and to try to assess whether there were any likely toxic hazards associated with this form of orthopaedic treatment.

Preliminary Investigation.-As a sensitive analytical technique based on neutron activation was available for analysis of cobalt in hair and samples could easily be collected the concentration in hair of 16 patients with T.H.R.s and 20 controls was measured. The mean cobalt concentration in the controls was 0.22 (range 0.07-0.49) p.p.m. and in the patients with implants 0.42 (range $0.06-2 \cdot 3$ ) p.p.m.; the difference between these means is not statistically significant. The experiment did not show a greater concentration of cobalt in patients generally, but as three patients had cobalt concentrations well outside the range of control values it is possible that in certain subjects the implant does give rise to a raised cobalt level in the body. It was therefore decided to undertake additional experiments in which the changes in concentration of cobalt and chromium due to wear products could be studied in selected patients.

Sampling Programme.-Virtually no quantitative information existed on the rate of wear of implants in vivo under load conditions. $C$ cast alloy T.H.R.s which have been in the body for a few years show no visible signs of wear, and weight changes have not yet been detected. It is known from animal studies that the liver and kidney take up the largest proportions of cobalt and chromium administered by mouth or by injection into a vein. These organs cannot be readily sampled before or after an operation, and for administrative reasons postmortem samples are also difficult to collect from patients with implants. It was therefore decided to monitor changes in blood and urine concentration before and after the operation for a selected number of patients. By this means the changes in concentration could be attributed to the loss of metal from the implant. After establishing equilibrium in the body the concentration of cobalt and chromium in urine is a reasonable guide to the wear rate of the implant. It was decided to take at least two samples of blood and urine before the operation and further samples after three weeks and at three and 12 months whenever possible. All samples were taken by J.T.S. at the Royal National Orthopaedic Hospital, Stanmore. In 
order to minimize the risk of contamination, since plastic syringes may be contaminated with chromium from mould tools, blood samples $(4 \mathrm{ml})$ were allowed to drip from a vein through a platinum-iridium needle and plastic tube into a cleaned silica tube. Urine samples were collected in clean plastic bottles. The blood samples were immediately freezedried without the addition of anticoagulants or other reagents. To date, the longest follow-up of patients with sampling is 32 months and is continuing.

Analytical Procedure.-The freeze-dried blood samples were suitable for irradiation without any further treatment, while for urine a $10-\mathrm{ml}$ sample was evaporated to dryness in a silica tube. The samples were irradiated together with a standard containing a known quantity of cobalt and chromium in the HERALD reactor for five days at a flux of $2 \times 10^{12}$ neutrons $/ \mathrm{sec} / \mathrm{cm}^{2}$ After irradiation the samples were stored for seven days to allow the bulk of the sodium-24 activity to decay, then cobalt and chromium were separated radiochemically and the induced activity was measured by gamma spectrometry. The concentration of cobalt and chromium was determined by comparing the activity of the samples with that of the standard. The reliability of the method was checked by analysing samples of blood and urine to which additional known quantities of cobalt and chromium had been added.

\section{Results}

The change in concentration of cobalt and chromium in blood and urine was observed in 12 patients-9 with all $C$ cast alloy T.H.R.s and 3 with T.H.R.s composed of $C$ cast alloy articulating with RCH 1,000 high molecular weight polyethylene. The mean concentration of cobalt and chromium in blood was calculated before and after insertion of the two types of implant. The results are set out in table $I$. The difference for cobalt and chromium concentration in the all metal T.H.R.s is statistically significant, but the limited data available for the metallic polyethylene T.H.R.s do not indicate a significant difference. The ratio of increase in concentration in blood was similar to the ratio of the metals in the alloy.

TABLE I-Analysis of Blood

\begin{tabular}{|c|c|c|c|c|}
\hline \multirow{2}{*}{\multicolumn{2}{|c|}{ Prosthesis }} & \multirow{2}{*}{ Element } & \multicolumn{2}{|c|}{ Average Concentration ( $\mu \mathrm{g} / 1)}$. \\
\hline & & & Preop. & Postop. \\
\hline $\begin{array}{l}\text { Cast alloy/RCH } 1000 \\
\text { Hip joint } \\
\text { All C cast alloy } \\
\text { Hip joint }\end{array}$ & $\begin{array}{l}\because \\
\because \\
\because\end{array}$ & $\begin{array}{l}\text { Cobalt } \\
\text { Chromium } \\
\text { Cobalt } \\
\text { Chromium }\end{array}$ & $\begin{array}{l}0.7(5) \\
1.8(5) \\
0.6(20) \\
1.4(20)\end{array}$ & $\begin{array}{l}0.3(6) \\
2 \cdot 0(6) \\
6 \cdot 5(32) \\
3 \cdot 9(32)\end{array}$ \\
\hline
\end{tabular}

Figures in parentheses indicate number of samples examined.

The data for urine given in table II present a similar picture. The difference between cobalt and chromium before and after the insertion of the all metal T.H.R.s is significant, while the very limited data available for the metallic/polyethylene T.H.R.s suggest that there was no increase in either cobalt or chromium.

The change in concentration of cobalt and chromium with

TABLE II-Analysis of Urine

\begin{tabular}{|c|c|c|c|c|}
\hline \multirow{2}{*}{\multicolumn{2}{|c|}{ Prosthesis }} & \multirow{2}{*}{ Element } & \multicolumn{2}{|c|}{ Average Concentration $(\mu \mathrm{g} / 1)$} \\
\hline & & & Preop. & Postop. \\
\hline $\begin{array}{l}\text { C cast alloy/RCH } 1000 \\
\text { Hip joint } \\
\text { All C cast alloy } \\
\text { Hip joint }\end{array}$ & $\begin{array}{l}\because \\
\because \\
\cdots\end{array}$ & $\begin{array}{l}\text { Cobalt } \\
\text { Chromium } \\
\text { Cobalt } \\
\text { Chromium }\end{array}$ & $\begin{array}{l}-\overline{-} \\
0 . \overline{5(10)} \\
0.4(9)\end{array}$ & $\begin{aligned} 0 \cdot 7(3) \\
1 \cdot 2(2) \\
24 \cdot 0(25) \\
6 \cdot 2(25)\end{aligned}$ \\
\hline
\end{tabular}

Figures in parentheses indicate number of samples examined.
$=$ No sample.
TABLE III-Typical Changes of Cobalt and Chromium Concentration with Time in Blood, Urine, and Hair

\begin{tabular}{|c|c|c|c|c|c|c|c|}
\hline & \multirow{2}{*}{\multicolumn{2}{|c|}{$\begin{array}{l}\text { Elapsed } \\
\text { Time } \\
\text { (Days) }\end{array}$}} & \multicolumn{2}{|c|}{ Blood $(\mu g / 1)}$. & \multicolumn{2}{|c|}{ Urine ( $\mu \mathrm{g} / \mathrm{l})}$. & \multirow{2}{*}{$\underset{\text { (p.p.m.) }}{\text { Cobair }}$} \\
\hline & & & Cobalt & Chromium & Cobalt & Chromium & \\
\hline \multicolumn{8}{|c|}{ Case 1-Bilateral T.H.R. (All C cast Alloy) } \\
\hline $\begin{array}{l}-2 \\
-1 \\
21 \\
47 \\
96, \\
113 \\
190 \\
400\end{array}$ & $\begin{array}{l}\because \\
\because \\
\ddot{2} \\
2 \text { Op. } \\
\because \\
\because\end{array}$ & $\begin{array}{l}\ldots \\
\cdots \\
\ldots \\
\cdots \\
\cdots \\
\cdots\end{array}$ & $\begin{array}{l}0.1 \\
0.1 \\
7.1 \\
1.8 \\
3.5 \\
0.7 \\
5.6 \\
4.5\end{array}$ & $\begin{array}{l}1.1 \\
0.9 \\
9.1 \\
0.5 \\
4.4 \\
5.8 \\
6.1 \\
3.3\end{array}$ & $\begin{array}{r}0.7 \\
0.5 \\
49.0 \\
46.0 \\
2.3 \\
6.5 \\
14.0 \\
15.0\end{array}$ & $\begin{array}{l}0.6 \\
0.2 \\
7.3 \\
4.7 \\
0.6 \\
2.6 \\
4.6 \\
6.2\end{array}$ & $\begin{array}{l}0.04 \\
0.03 \\
0.17 \\
0.17 \\
0.09 \\
0.10 \\
-\end{array}$ \\
\hline \multicolumn{8}{|c|}{ Case 2-Unilateral T.H.R. (All C Cast Alloy) } \\
\hline $\begin{array}{r}-2 \\
-1 \\
15 \\
78 \\
395\end{array}$ & $\begin{array}{l}\cdots \\
\cdots \\
\cdots \\
\cdots\end{array}$ & $\begin{array}{l}\ldots \\
\cdots \\
\cdots\end{array}$ & $\begin{array}{r}1.1 \\
0.3 \\
1.6 \\
12.0 \\
16.0\end{array}$ & \begin{tabular}{r|}
0.8 \\
1.5 \\
1.6 \\
4.9 \\
15.0
\end{tabular} & $\begin{array}{r}0.7 \\
0.8 \\
0.4 \\
14.0 \\
73.0\end{array}$ & $\begin{array}{r}* \\
0.5 \\
1.4 \\
2.3 \\
26.0\end{array}$ & $\begin{array}{l}\bar{Z} \\
0.03 \\
0.19 \\
0.07\end{array}$ \\
\hline \multicolumn{8}{|c|}{ Case 3-Bilateral T.H.R. 1st all C Cast Alloy, 2nd C Cast Alloy/RCH 1000} \\
\hline $\begin{array}{r}-3 \\
-1 \\
20 \\
83 \\
182, \\
289\end{array}$ & $\begin{array}{l}\because \\
\because \\
\ddot{2 n d} \text { Op. } \\
\ldots\end{array}$ & $\begin{array}{l}. \\
\cdots \\
\cdots \\
. .\end{array}$ & $\begin{array}{r}1 \cdot 8 \\
0.2 \\
3.0 \\
22 \cdot 0 \\
14 \cdot 0\end{array}$ & $\begin{array}{l}\overline{2.8} \\
2 \cdot 1 \\
6.2 \\
\overline{8.5}\end{array}$ & $\begin{array}{r}\overline{0.2} \\
9 \cdot 5 \\
61.0 \\
44.0\end{array}$ & $\begin{array}{r}\overline{0.2} \\
2.1 \\
11.0 \\
15.0\end{array}$ & $\begin{array}{r}0.15 \\
0.12 \\
0.12 \\
0.12 \\
=\end{array}$ \\
\hline
\end{tabular}

*Sample lost. - - = No Sample.

time is shown in table III for three typical patients with all metal T.H.R.s. The metal concentrations remained high after one year and suggested that these raised levels would persist indefinitely.

It may be inferred from tables I and II that with metallic polyethylene T.H.R.s there is no significant wear and/or corrosion of the metal component. We are unable to provide data concerning the wear of the polyethylene component. As regards all metal T.H.R.s there is wear of the components with dissolution of the wear products.

\section{Discussion}

By combining the information obtained in this study with others on animals it is possible to predict tentatively the change in concentration of cobalt and chromium in certain organs. Cook et al. (1956) showed for oral administration of cobalt-60, and Comar et al. (1946) for both oral and intraveneous injection, that cobalt is excreted rapidly from the body (biological half life nine days). Therefore the patients in this study will be in equilibrium with respect to cobalt and the excretion rate of cobalt in urine will be equal to the rate of wear of the implant. The maximum excretion rate observed has been about $100 \mu \mathrm{g} /$ day, although the average has been only $40 \mu \mathrm{g} /$ day.

The distribution of cobalt in the organs of animals after continuous administration of cobalt was measured by Comar et al. (1946) and Cook et al. (1956). The cobalt found in the liver was $33 \%$ of that passing through the gut; $5 \%$ was found in the kidneys and the remainder was distributed throughout the body at a low concentration. If this experience with animals can be related to man then the maximum quantity of cobalt in the liver in equilibrium will be increased by $430 \mu \mathrm{g}$ with an average increase of $200 \mu \mathrm{g}$. If the liver is assumed to weigh $1,700 \mathrm{~g}$ the maximum increase in concentration found in this study would be 0.25 p.p.m. and the average 0.12 p.p.m. The increase in concentration in kidney is similar to that in liver but less for all other organs.

The data on the distribution of chromium in the body are sparse. Examination of tissues removed from around a major joint replacement using an electron probe analysis technique showed that there was preferential retention of chromium. In the recommendation of the International Commission on Radiological Protection (1959) a biological half life of 600 days is calculated by indirect methods and the distribution of 
chromium throughout the body is fairly uniform. With these assumptions the maximum increase in concentratoin of chromium in equilibrium throughout the whole body is calculated to be 0.5 p.p.m. and the average increase 0.2 p.p.m. Although the assumptions may have been adequate for giving guidance on radiological protection they are of doubtful value for determining the change in concentration of chromium in organs due to wear products from implants. It is therefore suggested that further work should be undertaken to check the biological half life and the distribution of chromium in the body.

We are most grateful for the help given by Dr. J. Cook, of the Royal National Orthopaedic Hospital, Stanmore, and Mrs. B. Roantree, who has been associated with various clinical aspects of this work.

\section{References}

Comar, C. L., Davis, G. K., and Taylor, R. F. (1946). Archives of Biochemistry, 9, 149.

Cook, M. J., Morgan, K. Z., and Barkow, A. G. (1956). American fournal of Roentgenology, Radium Therapy, and Nuclear Medicine, 9, 149.

De Moraes, S., and Mariano, M. (1967). Medicina y Farmacia Exp. 16, 441. Gardner, F. H. (1953). Fournal of Laboratory and Clinical Medicine, 41, 56. Hall, J. L., and Smith, E. B. (1968). Medical Tribune International Edition, 3, 1 .

Holly, R. G. (1955). Fournal of the American Medical Association, 158, 1349. International Commission on Radiological Protection (1959). Oxford, Pergammon Press. Publication 2.

Kriss, J. P., Carnes, W. H., and Gros, R. T. (1955). Fournal of the American Medical Association, 157, 117.

McKenzie, A. W., Aitken, C. V. E., and Ridsdill-Smith, R. (1967). British

Medical fournal, 4, 36.

Schroeder, H. A., and Nason, A. P. (1969). Journal of Investigative Dermatology, 53, 71 .

Weissbecker, L., (1950). Medizinische Monatsschrift, Suppl. No. 9.

\section{MEDICAL MEMORANDA}

\section{Mumps Pancreatitis without Parotitis}

\section{K. NAFICY, R. NATEGH, H. GHADIMI}

British Medical fournal, 1973, 1, 529

Though mumps pancreatitis without parotitis has been reported in adults (O'Brien et al., 1965; Witte and Schanzer, 1968) we have not seen it in children. We therefore report here two cases of mumps pancreatitis in children under 10 years of age, in one of which pancreatitis was the only clinical manifestation of mumps virus infection.

\section{Case 1}

The patient, a 9-year-old girl, was admitted to hospital complaining of sudden onset eight hours previously of severe abdominal pain, vomiting, and cold perspiration. She was pale, had generalized abdominal tenderness, more pronounced around the umbilicus, with muscular guarding, pyrexia of $38.2^{\circ} \mathrm{C}$, a pulse rate of $140 / \mathrm{min}$, and a blood pressure of $86 / 54 \mathrm{~mm} \mathrm{Hg}$. Blood examination showed $\mathrm{Hb} 13.2 \mathrm{~g} /$ $100 \mathrm{ml}$, W.B.C., $12,000 / \mathrm{mm}^{3}$ with polyneutrophil $36 \%$, band cells $4 \%$, lymphocytes $55 \%$, and monocytes $5 \%$. Urine analysis was normal and lungs were clear on $x$-ray examination. Alanine transaminase and aspartate transaminase were 48 and 65 units respectively, and total serum bilirubin was $1.2 \mathrm{mg} / 100 \mathrm{ml}$. A history of mumps in an older brother 20 days before suggested a diagnosis of mumps pancreatitis. Serum amylase was found to be 1,600 Somogyi units and a 12-hour urine excretion of amylase was 3,200 Somogyi units.

The patient responded slowly to intravenous fluid and intravenous analgesics and antispasmodics. Severe abdominal pain and cramps continued for $\mathbf{4 8}$ hours, gradually becoming episodic and milder. Oral feeding started after 36 hours and after six days she was almost free of pain. The serum amylase on the third, fifth, and seventh days was $1,600,2,400$, and 1,600 Somogyi units respectively. She was discharged on the seventh day. She complained of occasional abdominal

\footnotetext{
Graduate School of Public Health and Institute of Public Health Research, University of Teheran, Iran

K. NAFICY, M.D., Associate Professor and Director

R. NATEGH, M.D., Associate Professor

Children's Clinic, 84 Takhte Jamshid, Teheran, Iran

H. GHADIMI, M.D., Paediatrician
}

cramps up to four weeks after discharge. Serum obtained on admission and 21 days later contained neutralizing antibody to mumps virus at titres of $1 / 4$ and $1 / 32$ respectively.

\section{Case 2}

The second patient, a 6-year-old boy, presented with similar signs and symptoms, and the clinical findings were similar except for the presence of bilateral parotitis, which made the diagnosis obvious. He was discharged from hospital after eight days. Sixteen days later he complained of only occasional abdominal cramps. Serum obtained on admission and 24 days later contained neutralizing antibody to mumps virus at titres of $1 / 4$ and $1 / 16$ respectively.

The neutralizing antibody titres were determined in both cases by the standard neutralization technique (Lennette and Schmidt, 1964) using chick cell cultures and Jerry Lean strain of mumps virus.

\section{Comment}

The diagnosis of mumps in the absence of parotitis is difficult and only virological study can confirm it. Only two out of 90 cases of pancreatitis reported by Joske (1955) were listed as due to mumps, but the aetiology was unknown in 22 cases and perhaps virological study would have shown some to have been due to mumps without parotitis.

Comparing our two cases of mumps pancreatitis in children with those reported in adults (O'Brien et al., 1965; Witte and Schanzer, 1968) it seems that the disease is milder in children and recovery occurs within a shorter period. The clinical picture of sudden onset of generalized abdominal pain with pallor, nausea, vomiting, tachycardia, and abdominal wall guarding is not only that of pancreatitis. We think, however, that mumps pancreatitis without parotitis may be more common than is thought, and it should be looked for in any patient presenting with an acute abdominal condition.

This study was partly supported by the funds of the Public Health Research Project of the Iranian Ministry of Health and Plan Organization.

\section{References}

Joske, R. A. (1955). British Medical Fournal, 2, 1477.

Lennette, E. H., and Schmidt, N. J., (editors) (1964). Diagnostic Procedures for Viral and Rickettsial Diseases, 3rd edn., p. 119. Washington, American Public Health Association.

O'Brien, P. K., Smith, D. S., and Galpin, O. P. (1965). British Medical Fournal, 2, 1529.

Witte, C. L., and Schanzer, C. B. (1968). Fournal of the American Medical Association, 203, 1068. 